\title{
Reinforcing involvement of NK cells in psoriasiform dermatitis animal model
}

\author{
MIHAELA SURCEL ${ }^{1,2}$, ADRIANA NARCISA MUNTEANU ${ }^{1,2}$, RADU-IONUȚ HUICĂ $\breve{~}^{3}$, \\ GHEORGHIȚA ISVORANU ${ }^{1}$, IOANA RUXANDRA PÎRVU ${ }^{1}$, CAROLINA CONSTANTIN ${ }^{1,4}$, \\ OVIDIU BRATU ${ }^{3}$, CONSTANTIN CĂRUNTU ${ }^{3}$, ISADORA ZAHARESCU ${ }^{5,6}$, \\ LUCICA SIMA ${ }^{7}$, MARIETA COSTACHE ${ }^{2}$ and MONICA NEAGU ${ }^{1,2,4}$
}

\begin{abstract}
${ }^{1}$ Immunobiology Laboratory, 'Victor Babes' National Institute of Pathology, 050096 Bucharest; ${ }^{2}$ Doctoral School of Biology, Faculty of Biology, University of Bucharest, 050095 Bucharest; ${ }^{3}$ Division of Cellular and Molecular Biology and Histology, 'Carol Davila' University of Pharmacy and Medicine, 050474 Bucharest;

${ }^{4}$ Department of Pathology, Colentina University Hospital, 020125 Bucharest; ${ }^{5}$ Doctoral School Medicine, Titu Maiorescu University, 040441 Bucharest; ${ }^{6}$ Department of Anesthesiology and Intensive Care, Witting Clinical Hospital, 010243 Bucharest; ${ }^{7}$ Research Laboratory, Romvac Company S.A, 077190 Voluntari, Romania
\end{abstract}

Received June 13, 2019; Accepted August 8, 2019

DOI: $10.3892 / \mathrm{etm} .2019 .7967$

\begin{abstract}
Psoriasis (Ps) is a chronic inflammatory immunemediated disease with skin and joint manifestations, characterized by abnormal and rapid proliferation of keratinocytes and infiltration of psoriatic lesions with immune cells. Extensive literature suggests that Ps is a T-cell mediated disease its pathogenesis being highly related to innate and adaptative immune cells. Although natural killer (NK) cells are involved in the inflammatory process of Ps through pro-inflammatory cytokine secretion (tumor necrosis factor $\alpha$,
\end{abstract}

Correspondence to: Dr Monica Neagu, Immunobiology Laboratory, 'Victor Babes' National Institute of Pathology, 99-101 Splaiul Independentei, 050096 Bucharest, Romania

E-mail: neagu.monica@gmail.com

Abbreviations: APC, allophycocyanin; BD, Becton Dickinson; $\mathrm{CD}$, cluster of differentiation; DC, dendritic cell; EDI, erythema, desquamation and induration; FACS, fluorescence-activated cell sorting; FBS, fetal bovine serum; H\&E, hematoxylin and eosin; FITC, fluorescein isothiocyanate; IFN, interferon; Ig, immunoglobulin; IL, interleukin; IMQ, imiquimod; K2-EDTA, kalium 2 ethylenediaminetetraacetate; KGF, keratinocyte growth factor; KLRG1, killer cell lectin-like receptor G1; LC, langerhans cell; NK, natural killer cells; PASI, psoriasis area severity index; PB, peripheral blood; $\mathrm{PE}$, phycoerythrin; $\mathrm{PE} / \mathrm{Cy}$, phycoerythrin complex with cyanine; PerCP/Cy, peridinin chlorophyll protein complex with cyanine; R, receptor; RBC, red blood cell; RPMI, Roswell Park Memorial Institute; SD, standard deviation; SW/BW, spleen weight/ body weight; Th, helper T cells; TLR, Toll-like receptor; TNF, tumor necrosis factor; UV, ultraviolet; VEGF, vascular endothelial growth factor

Key words: NK cells, imiquimod, psoriasiform dermatitis, inflammation interferon $\gamma$ ), their role in this pathology is not yet fully elucidated. In order to study the involvement of NK subpopulations in the pathogenesis of Ps we used the imiquimod-based mouse model of psoriasiform dermatitis and NK cells complex phenotype patterns from peripheral blood (PB) and spleen were investigated. Skin inflammation and the disease severity were assessed using in vivo measurements (erythema, desquamation and induration parameters, PASI modified score), splenomegaly assessment and histopathological evaluation. Phenotypic characterization of NK cells in imiquimod (IMQ)-treated mice was performed by flow cytometry, for both PB and spleen cell suspension. A large panel of surface markers was used: maturation and activation markers [cluster of differentiation (CD)49b, CD11b, CD43, CD27, KLRG1, CD335, CD69, CD28, gp49R, CD45R, CD11c] and markers for cytokine receptors (CD25, CD122, CD132). Our experimental data showed important differences in IMQ-treated mouse NK cell phenotype as compared to control group. The maturation markers (CD11b, CD43, CD27, KLRG1) were found increased on NK cells, in periphery and spleen, while CD49b+NK1.1 ${ }^{+}$ was significantly lower, and the alterations correlated with the severity of the disease. Our findings reflect the immune engagement toward activatory profile of NK cells and draw attention to evaluating Ps intensity correlated with the mature profile of circulating NK cells.

\section{Introduction}

Psoriasis (Ps) is a chronic inflammatory immune-mediated disease with skin and joint manifestations (1). Histologically it is characterized by abnormal and rapid proliferation of keratinocytes and infiltration of psoriatic lesions with immune cells, especially T cells and dendritic cells (DC) (2). Globally, Ps affects $2-4 \%$ of the adult population, especially Caucasians, women and men equally, and $0.1-1 \%$ of children; prevalence is dependent on age, ethnicity, geographic area, 
and environmental factors (3). It can start at any age, from childhood to old age, but $75 \%$ of those affected developed the disease before the age of 40 years. Psoriatic arthritis affects up to $30 \%$ of patients diagnosed with Ps (children and adults) and approximately $50 \%$ of people who develop Ps observe changes in the nails (from fingers and/or toes). Ps is associated with several co-morbidities which include diabetes mellitus (4), obesity (5), hypertension (6), and cardiovascular diseases (7). Due to visible lesions, Ps reduces the self-esteem of patients and leads to a decrease in quality of life, depression and suicidal ideations (8).

Ps has a multi-factorial aetiology with important immunologic, genetic and environmental components (9). The main risk factors are ultraviolet (UV) exposure $(10)$, medications $(11,12)$, smoking (13), diet and obesity (14), alcohol intake (15), infections (16), and stress (17). It may occur in mild, moderate or severe forms, with lesions varying in appearance depending on the type of Ps: plaque (90\%), guttate, pustular, inverse, and erythrodermic. Ps is unique to each patient, the severity of Ps lesions varies from person to person and the treatment depends on the type of Ps, severity, the area where Ps is located, patient age and medical history, and the effect that Ps has on the patient (physically and emotionally). Besides classic Ps therapies, such as topical treatment (for mild forms), UV light therapy (for moderate to severe forms) and systemic treatments (for moderate to severe Ps which has not successfully responded to topical treatments or UV therapy) (18) biological therapies (19) have entered the panel of therapeutical approaches. Biologic treatments such as etanercept, adalimumab, infliximab [anti-tumor necrosis factor (TNF)- $\alpha$ ], ustekinumab [anti-interleukin (IL)-12/-23], secukinumab (anti-IL-17) are used for patients with severe Ps who have not responded to systemic treatments such as methotrexate, ciclosporin and acitretin. Recent studies suggest the role of complementary or alternative medicine products on the psoriatic lesions $(20,21)$. Despite these various treatments, Ps remains incurable but clinically manageable.

Extensive literature suggests that Ps is a T-cell mediated disease and in its pathogenesis the innate and adaptative immune cells are highly involved; an important role is played by different $\mathrm{T}$ helper lymphocyte (Th) subsets accompanied by several pro-inflammatory cytokines which maintain the chronic inflammatory status (22). Although it is considered a $\mathrm{T}$ cell mediated inflammatory disease, several cell types from the adaptive and innate immunity arm, as well as non-immune cells are highly involved. DC, natural killer (NK) cells and macrophages from the innate immunity arm are involved in the pathogenesis of Ps, establishing intense interactions with keratinocytes and endothelial cells (9). The interactions between immune cells [T cells, DC, NK cells, Langerhans cells (LC), macrophages] and non-immune cells (hyperproliferative keratinocytes) are mediated by immune-related molecules (cytokines, chemokines) and non-immune-related molecules [vascular endothelial growth factor (VEGF), keratinocyte growth factor (KGF)], all these interactions lead to development of psoriatic lesions (23). Initiation of psoriatic events occurs when, under the action of triggering factors (genetics, environmental, skin injury, infections), non-specific immune cells (NK cells, macrophage, plasmacytoid DC) and keratinocytes secrete TNF $\alpha$, IFN $\gamma$, IL-1 $\beta$, IL-6 which will activate myeloid DC. The activated myeloid DC are able to secrete IL-12 and IL-23, which will further cause differentiation of resident T cells into Th1, Th17 and Th22 cells. These effector Th subsets will release TNF $\alpha$, IFN $\gamma$, IL-17A/F and IL-22 therefore activating the keratinocytes which will produce mainly pro-inflammatory cytokines (TNF $\alpha$, IL-1 $\beta$, IL-6), chemokines (CXCL9, 10, 11) and LL-37 (an antimicrobial peptide considered to be a possible autoantigen in Ps). Activated keratinocytes, by releasing a panel of chemokines, will promote the recruitment and activation of neutrophils and macrophages, thus propagating and maintaining the skin inflammation (24).

In humans, NK cells are defined as cluster of differentiation (CD) $56^{+} \mathrm{CD}^{-}$cells, and can be divided into CD56 ${ }^{\text {bright }} \mathrm{NK}$ cells (with predominantly immunoregulatory properties) and CD56 ${ }^{\text {dim }}$ NK cells (with marked cytotoxic function) (25). NK cells were found in the inflammatory infiltrate in psoriatic skin lesions and many cytokines known to be crucial of Ps are related to NK biology and are either released by NK cells (IFN $\gamma$, TNF- $\alpha$, and IL-22) or are important in their activation (IL-15, IL-18, IL-12, and IL-23). Although NK cells are involved in the inflammatory process of Ps through these pro-inflammatory cytokines, their role in this pathology is not yet fully elucidated (26). Especially known for their ability to recognise and kill viral or cancer cells, NK cells are also involved in some other cutaneous pathologies such as atopic dermatitis (27), pemphigus vulgaris (28) and alopecia areata (29).

In order to aid information to the pathogenesis of Ps and to identify potential therapeutic targets, numerous experimental models performed in vitro and/or in vivo were developed, each of them heaving advantages and disadvantages. In vivo mouse models of Ps can be grouped into spontaneous (chronic proliferative dermatitis cpdm/cpdm, flaky skin $T t c f^{s n} / T_{t c f}{ }^{s n}$, homozygous asebia $S c d 1^{a b} / S c d 1^{a b}$ ), genetically engineered (Involucrin/IFN $\gamma, \mathrm{K} 14-\mathrm{KGF}, \mathrm{K} 14-\mathrm{VEGF}$, and K5-Stat3C), xenotransplantation (human skin on SCID mice, on athymic nude mice or on AGR129 mice), and directly induced [intradermal injection of IL-23, 5\% imiquimod (IMQ)] models (30).

In recent years, one of the most used experimental models of Ps, is IMQ-based mouse model of psoriasiform dermatitis. This model has not only reduced the costs and high reproducibility but also can furnish relevant results. IMQ has a nucleoside [1-isobutyl-1H-imidazo(4,5-c)quinolin-4-amine] analogue of imidazoquinoline family, is used in clinics for its anti-viral and anti-neoplastic properties in the treatment of human papilloma virus-derived genital warts (31), squamous cell carcinoma (32) and actinic keratosis (33).

Our prior published results using IMQ animal model showed that there is a clear alteration of lymphocyte percentages in peripheral blood (PB) and in secondary organs, pinpointing towards NK lymphocyte deregulation (34). As NK cells are one of the main immune populations that balance innate and adaptive immunity we enlarged the evaluated subtypes of NK subpopulations identified in PB and in secondary lymph organs seeking to establish the best pattern of NK phenotype related to the evolution of psoriatic lesions.

Acknowledging the importance of NK lymphocyte population in developing psoriatic lesions we used an IMQ-based mouse model of psoriasiform dermatitis to study the NK cell phenotype from PB and spleen cell suspensions detecting the phenotypes described in Table I. 


\section{Materials and methods}

IMQ-based mouse experimental model of psoriatic dermatitis. C57BL/6 mice (Jackson Laboratory, Bar Harbor, ME) were provided by the Animal Husbandry from 'Victor Babes, National Institute of Pathology. They were accommodated in individual cages in an open cage system, in a temperature-controlled, air-conditioned animal house $\left(20 \pm 4^{\circ} \mathrm{C}\right.$, $55 \pm 10 \%$ humidity) with a $12 / 12$-light /dark cycle, and received food and water ad libitum. The animals were monitored daily. The study design was approved by the Ethics Committee from 'Victor Babeș' Institute, and the experiments were done in accordance with recognized principles of Laboratory Animal Care in the framework of EU Directive 2010/63/EU for animal experiments (35).

IMQ-based mouse model of psoriasiform dermatitis was replicated according to the protocols described in literature (36). Two groups of C57BL/6 mice were considered (1:1 sex ratio, 8-11 weeks old): i) IMQ group: received a daily topical dose of $62.5 \mathrm{mg}$ IMQ cream (5\% Aldara Cream; MEDA $\mathrm{AB}$ Sweden) on the shaved back region for 5 consecutive days (6 mice); and ii) Control group: no topical treatment (5 mice).

Erythema, skin scaling and thickening were monitored daily on a $0-4$ scale $(0$, none; 1 , slight; 2 , moderate; 3 , marked; and 4, very marked) and a modified PASI score (erythema + skin scaling + thickening) was calculated daily in order to score the inflammation due to IMQ treatment. Body weight was measured on the first day of experiment and prior to sacrifice. At the end of IMQ treatment (day 6) the mice were anesthetized (ketamine / acepromazine, 100/5 mg/kg, Ketaset; Wyeth/Fort Dodge Animal Health, Overland Park, KS, USA; Vedco, St. Joseph, MO, USA) and weighed. Blood was collected in K2-EDTA coated tubes (Microvette, Sarstedt AG \& Co.) by retro-orbital veni-puncture and then the mice were sacrificed for spleen and skin sampling. The spleens were removed and weighed immediately (Balance AEP-1500 A; Adam Equipment Co., Ltd.) in order to assess the splenomegaly. Further spleens were harvested in RPMI-1640 media with 5\% FBS (Biochrom $\mathrm{GmbH}$ ) and passed through a $70 \mu \mathrm{m}$ cell strainer (BD Falcon-BD Biosciences) to isolate the entire spleen cell populations. The spleen cell suspensions were centrifuged for $5 \mathrm{~min}$ at $350 \mathrm{xg}\left(20^{\circ} \mathrm{C}\right)$, resuspended in RBC Lysis Buffer (BioLegend), and incubated 5 min on ice. The lysis was stopped by adding $10 \mathrm{ml}$ Cell Staining Buffer (BioLegend). Cell suspensions were centrifuged for $5 \mathrm{~min}$ at $350 \times \mathrm{g}\left(20^{\circ} \mathrm{C}\right)$ and the cell pellet was resuspended twice in Cell Staining Buffer (BioLegend). Viable cells were counted and resuspended in Cell Staining Buffer (BioLegend) at $1 \times 10^{6}$ cells $/ \mathrm{ml}$. Skin samples were processed for histopathological assessment (fixed in 10\% buffered formalin, embedded in paraffin, sectioned in $5 \mu \mathrm{m}$ thick sections, stained with hematoxylin and eosin and examined by pathologists).

Flow cytometry analysis. NK cell phenotype was performed by flow cytometry, with an 8-color system setup, based on the expression of surface markers. EDTA-anticoagulated whole blood samples and spleen cell suspensions were incubated with TruStain fcX (anti-mouse CD16/32, isotype Rat $\operatorname{IgG2a}, \lambda$ ) antibody (BioLegend) in order to block non-specific antibody binding. After blocking, all samples
Table I. NK cell phenotype maturation, activation and cytokine receptor markers.

Maturation markers

\begin{tabular}{ll}
\hline $\begin{array}{l}\text { Precursors } \\
\text { Pre-NK }\end{array}$ & $\mathrm{CD} 27^{+} ; \mathrm{CD} 122^{-}$ \\
R-NK & $\mathrm{CD} 27^{+} ; \mathrm{CD} 122^{+}$ \\
Immature NK cells & \\
Stage A & $\mathrm{CD} 27^{+} ; \mathrm{CD} 122+$ \\
Stage B & $\mathrm{CD} 27^{+} ; \mathrm{CD} 122^{+} ; \mathrm{NK} 1.1^{+} ; \mathrm{CD} 43^{+}$ \\
Stage C & $\mathrm{CD} 27^{+} ; \mathrm{CD} 122^{+} ; \mathrm{NK} 1.1^{+} ; \mathrm{CD} 43^{+} ;$ \\
& $\mathrm{NKp} 46^{+}$ \\
Mature NK cells & $\mathrm{CD} 27^{+} ; \mathrm{CD} 122^{+} ; \mathrm{NK} 1.1^{+} ; \mathrm{CD} 43^{+} ;$ \\
Stage D & $\mathrm{NKp} 46^{+} ; \mathrm{CD} 49 \mathrm{~b}^{+}$ \\
& $\mathrm{CD} 27^{+} ; \mathrm{CD} 122^{+} ; \mathrm{NK} 1.1^{+} ; \mathrm{CD} 43^{-} ;$ \\
Stage E & $\mathrm{NKp} 46^{+} ; \mathrm{CD} 49 \mathrm{~b}^{+} ; \mathrm{CD} 11 \mathrm{~b}^{+}$ \\
& $\mathrm{CD} 27^{+} ; \mathrm{CD} 122^{+} ; \mathrm{NK} 1.1^{+} ; \mathrm{CD} 43 ;$ \\
Stage F & $\mathrm{NKp} 46^{+} ; \mathrm{CD} 49 \mathrm{~b}^{+} ; \mathrm{CD} 11 \mathrm{~b}^{+} ; \mathrm{KLRG} 1^{+}$ \\
&
\end{tabular}

Activation markers

CD335 (NKp46, NCR1); CD69; CD28; gp49R, CD45R

(B220); CD11c

Markers for cytokine receptors

CD25 (IL-2R $\alpha$ ); CD122 (IL-2R/IL-15R $\beta$ );

CD132 (common $\gamma$ chain)

NK, natural killer cells; IL, interleukin; CD, cluster of differentiation.

were incubated for $20 \mathrm{~min}$ at room temperature in the dark with the following monoclonal antibodies conjugated with fluorochromes (in the quantities indicated by the producers): FITC anti-mouse CD3e (clone 145-2C11, isotype Armenian Hamster IgG), PerCP/Cy5.5 anti-mouse CD11c (clone N418, isotype Armenian Hamster IgG), APC/Cy7 anti-mouse CD45R (B220) (clone RA3-6B2, isotype Rat IgG2a, $\kappa$ ), $\mathrm{PE} / \mathrm{Cy} 7$ anti-mouse CD69 (clone H1.2F3, isotype Armenian Hamster IgG), PE anti-mouse KLRG1 (clone 2F1, isotype Syrian Hamster IgG), PerCP/Cy5.5 anti-mouse/rat/human CD27 (clone LG.3A10, isotype Armenian Hamster $\operatorname{IgG}$ ), APC anti-mouse CD11b (clone M1/70, isotype Rat IgG2b, $\kappa$ ), $\mathrm{APC} / \mathrm{Cy} 7$ anti-mouse CD43 (clone RA3-6B2, isotype Rat IgG2a, $\kappa$ ), PE/Cy7 anti-mouse CD335 (NKp46) (clone 29A1.4, isotype Rat IgG2a, $\kappa$ ), PE anti-mouse CD132 (common $\gamma$ chain) (clone TUGm2, isotype Rat IgG2b, $\kappa$ ), PerCP/Cy5.5 anti-mouse CD122 (IL-2R/IL-15R $\beta$ ) (clone TM- $\beta 1$, isotype Rat IgG2b, $\kappa$ ), APC/Cy7 anti-mouse CD25 (IL-2R $\alpha$ ) (clone PC61, isotype Rat IgG1, $\lambda$ ), PE anti-mouse CD28 (clone 37.51, isotype Syrian Hamster IgG) (BioLegend), Brilliant Violet 510 anti-mouse NK1.1 (clone PK136, isotype Mouse IgG2a, $\kappa$ ) (BD Horizon, BD Biosciences), eFluor 450 anti-mouse CD49b (DX5) (clone DX5, isotype Rat IgM, ผ), eFluor 660 anti-mouse gp49R (clone H1.1) (eBioscience Inc.). After surface staining, red 


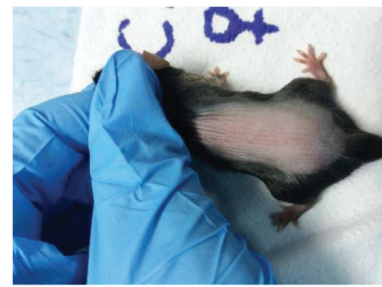

Day 1

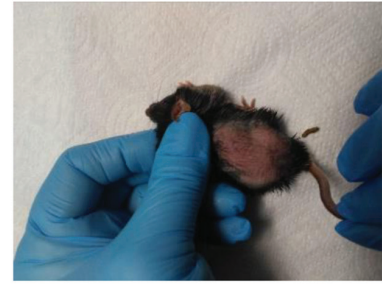

Day 4

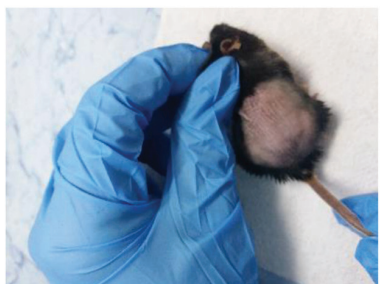

Day 2

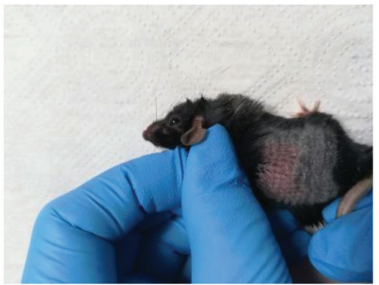

Day 5

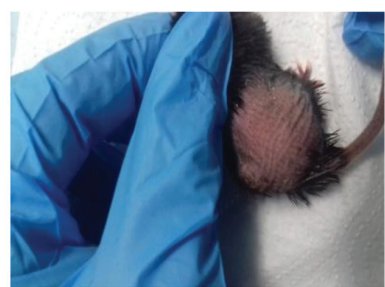

Day 3

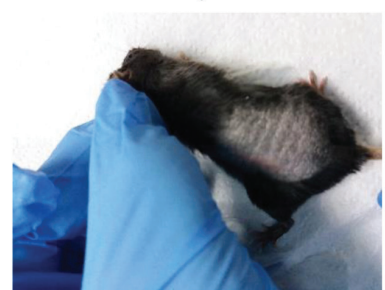

Day 6

Figure 1. The evolution of back skin inflammation during the IMQ-treatment. On day 1, the IMQ-based treatment was initiated, and on day 6 the mice were sacrificed. IMQ, imiquimod.

blood cells were lysed with RBC Lysis Buffer (BioLegend) for $10 \mathrm{~min}$ at room temperature in the dark, followed by centrifugation for $5 \mathrm{~min}$ at $350 \mathrm{x} \mathrm{g}$ at $20^{\circ} \mathrm{C}$. Cells were washed twice with Cell Staining Buffer (BioLegend) and analysed by flow cytometry. Non-specific fluorescence signals obtained due to spectral overlap were automatically compensated (UltraComp eBeads, Invitrogen by Thermo Fischer Scientific, Inc.) and unlabeled cells were used as negative controls. Data acquisition and analysis were performed on a BD FACSCanto II cytometer with BD FACSDiva v.6.1 software (BD Biosciences). Cytometer performances were checked using CST beads (BD Cytometer Setup \& Tracking Beads kit; BD Biosciences).

Statistical analysis. Statistical analysis was performed using Microsoft Excel. The results for spleen weight and body weight are presented as mean spleen weight $\pm \mathrm{SD}$, respectively mean ratio $\mathrm{SW}: \mathrm{BW} \pm \mathrm{SD}$. The flow cytometry data were expressed as percentages of NK1.1+ cells (mean values \pm SD), gated from CD $3 \varepsilon^{-}$lymphocytes. Student's t-test (two-tailed, assuming equal variance) was used to assess the differences between the experimental groups, and $\mathrm{P}<0.05$ was considered to indicate a statistically significant difference.

\section{Results}

Psoriasiform dermatitis mouse model induced by IMQ. IMQ-based mouse model of psoriasiform dermatitis was replicated according to the protocols described by us (34), by applying a daily topical dose of Aldara cream on the shaved back skin of C57BL/6 mice for 5 consecutive days. Skin inflammation and the disease severity were assessed using in vivo measurements (erythema, desquamation and induration parameters, PASI modified score), splenomegaly assessment and histopathological evaluation.

In vivo measurements of skin inflammatory parameters. Erythema, desquamation and induration parameters (EDI) were assessed to study the progress of skin inflammation and hence the disease severity by daily monitoring. EDI were scored daily on a scale from 0 to 4 : 0 , none; 1 , slight; 2 , moderate; 3 ,

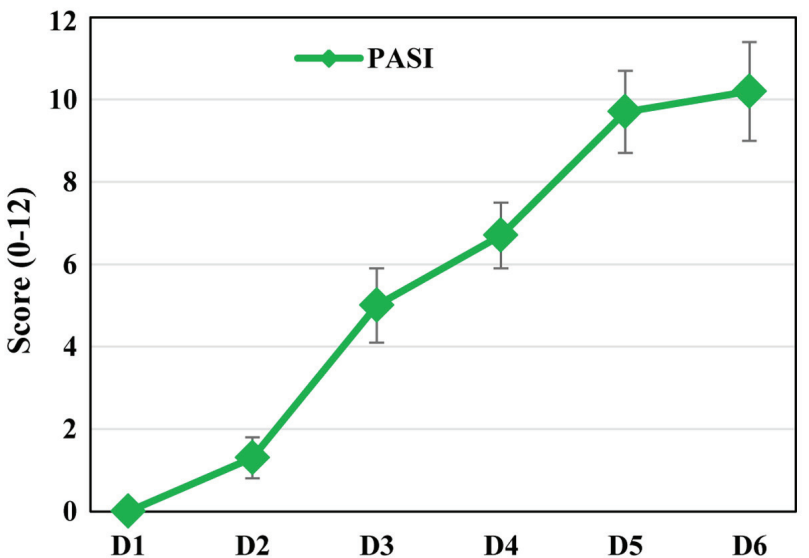

Figure 2. In vivo measurements of PASI cumulative score. PASI cumulative score was calculated daily by adding the scores obtained for erythema, skin

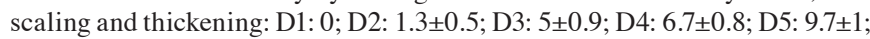
D6: $10.2 \pm 1.2$. The results are presented as mean score $\pm S D ; n=6$. $n$, number of mice; D, day; PASI, psoriasis area severity index.

marked; and 4, very marked. Fig. 1 presents a representative case of inflammation induced by IMQ and the EDI scoring for all the mice in the IMQ group matched the pattern previously published by us for this experimental model (34). As previously shown, all EDI parameters, erythema is the first parameter that can be scored after one day of IMQ applications, followed after another day by the subsequent registered parameters, thus starting from day 2, all EDI parameters are registered in all the animals subjected to IMQ (34).

As in psoriatic patients, in our animal model, the severity of inflammation was estimated based on a modified PASI score (0-12 scale), calculated daily by adding the independent daily scores obtained for EDI (the affected area was not taken into account). The PASI score had a progressive evolution during the IMQ-treatment (Fig. 2) matching the increased severity of the psoriatic lesions.

As the PASI score clearly depicted the evolution of the psoriatic lesions we evaluated the histopathology of psoriatic-like skin in our model. 

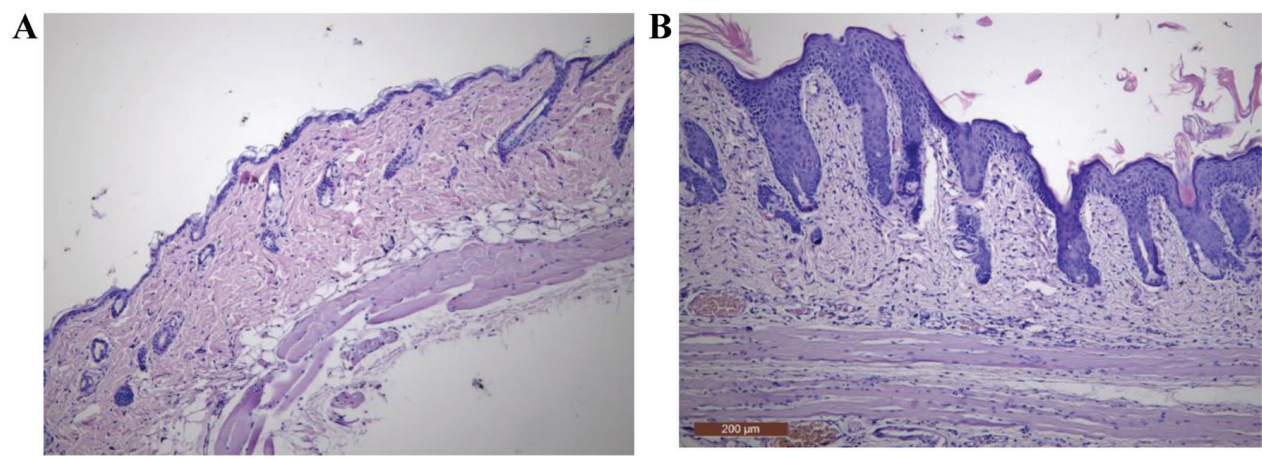

Figure 3. Histopathological evaluation of mouse skin samples (H\&E staining). (A) Normal skin. (B) IMQ-treated skin. IMQ treatment induced hyperkeratosis, parakeratosis, acanthosis and elongation of rete ridges (B). IMQ, imiquimod; H\&E, hematoxylin and eosin.

A

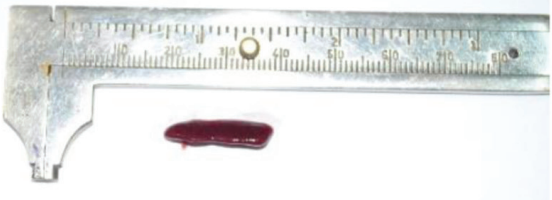

B

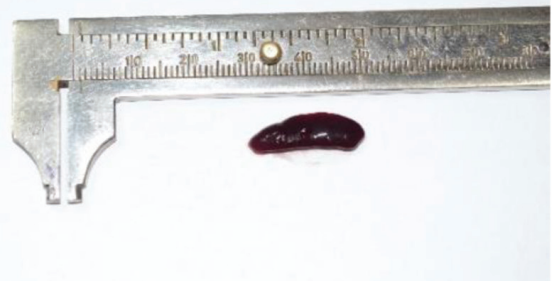

Figure 4. Representative images of splenomegaly evaluation. (A) Spleen harvested from a control mouse. (B) Spleen harvested from a mouse treated with IMQ-based cream. IMQ, imiquimod.
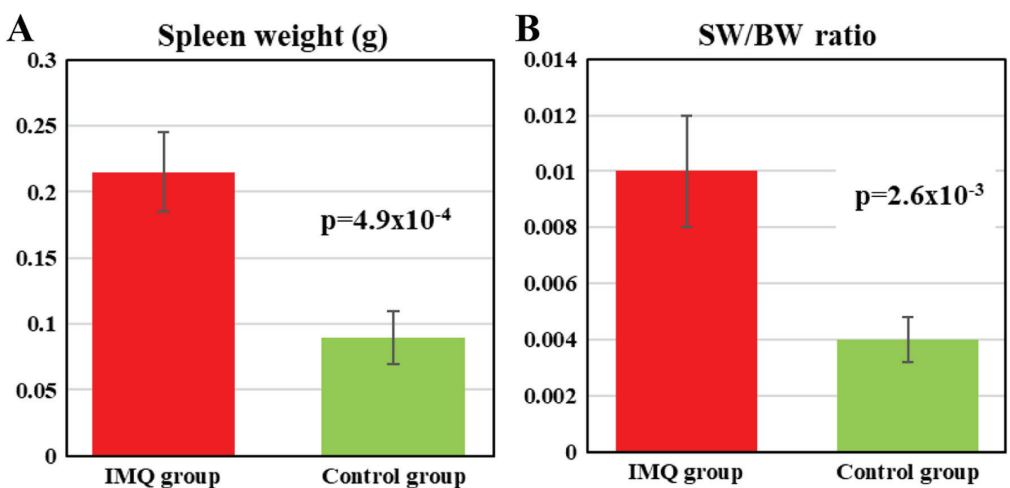

Figure 5. Splenomegaly assessment. (A) Weight of the spleens. The weight of the spleens for IMQ-treated mice $(0.215 \pm 0.03)$ and the control group $(0.09 \pm 0.02)$ is statistically different $\left(\mathrm{P}=4.9 \times 10^{-4}\right)$. (B) SW:BW ratio. The $\mathrm{SW}: \mathrm{BW}$ ratio for IMQ-treated mice $(0.010 \pm 0.002)$ and the control group $(0.004 \pm 0.0008)$ is statistically different $\left(\mathrm{P}=2.6 \times 10^{-3}\right)$. The results are presented as mean spleen weight $\pm \mathrm{SD}$, respectively, mean ratio $\mathrm{SW}: \mathrm{BW} \pm \mathrm{SD}$. IMQ, imiquimod; $\mathrm{SD}$, standard deviation; SW/BW, spleen weight/body weight.

Histopathological evaluation. After 5 days of treatment, IMQ-based cream induced pathological alterations in the epidermis, by compromising its integrity. Several histopathological features that are typical for human Ps, such as hyperkeratosis, parakeratosis, acanthosis and elongation of rete ridges were observed (Fig. 3B).

Splenomegaly assessment. At the end of the experiment (day 6) the mice were weighed and sacrificed; spleens from all the animals were removed and weighed in order to assess the splenomegaly, SW/BW ratio (spleen weight/total body weight) was calculated. The IMQ-treated mice SW was significantly higher compared to healthy mice (control group) $(0.215 \pm 0.03$ vs. $\left.0.09 \pm 0.02, \mathrm{P}=4.9 \times 10^{-4}\right)$ (representative measurement is presented in Figs. 4 and 5A). When assessing SW/BW ratio we found that in IMQ-treated mice this ratio was 2.5 times greater compared to control mice $(0.010 \pm 0.002$ vs. $0.004 \pm 0.0008$, $\mathrm{P}=2.6 \times 10^{-3}$; Fig. $\left.5 \mathrm{~B}\right)$.

NK cell phenotype in PB and spleen samples. To evaluate the immune populations that are circulating in the PB and that are resident in the secondary lymph organ such as the spleen, we have extensively characterized the NK cell phenotype from IMQ-psoriatic mice compared to control animals. Besides lineage markers such as CD161 (NK1.1) and CD3e, a large panel of surface markers was used as follows: i) maturation markers: CD49b (DX5), CD11b, CD43, CD27, KLRG1; 
Table II. Distribution of maturation markers on NK1.1+ cells in peripheral blood and spleen suspension.

\begin{tabular}{|c|c|c|c|c|c|c|}
\hline \multirow[b]{2}{*}{ Markers } & \multicolumn{3}{|c|}{ Peripheral blood } & \multicolumn{3}{|c|}{ Spleen suspension } \\
\hline & Control (mean $\pm \mathrm{SD})$ & IMQ group $($ mean $\pm \mathrm{SD})$ & $\mathrm{P}$-value & Control $($ mean $\pm \mathrm{SD})$ & IMQ group (mean \pm SD) & $\mathrm{P}$-value \\
\hline CD49b & $70 \pm 14.1$ & $57 \pm 5.8$ & NS & $69 \pm 4.2$ & $47 \pm 10.2$ & $\mathrm{P}=0.002$ \\
\hline CD11b & $92 \pm 1.8$ & $95 \pm 1.2$ & $\mathrm{P}=0.01$ & $74 \pm 1.4$ & $80 \pm 3.1$ & $\mathrm{P}=0.004$ \\
\hline CD43 & $93 \pm 2.6$ & $96 \pm 1.6$ & $\mathrm{P}=0.04$ & $82 \pm 3$ & $81 \pm 3.4$ & NS \\
\hline CD27 & $15 \pm 3.7$ & $17 \pm 1.9$ & NS & $30 \pm 3.7$ & $42 \pm 3.9$ & $\mathrm{P}=0.001$ \\
\hline KLRG1 & $63 \pm 7.6$ & $77 \pm 4.8$ & $\mathrm{P}=0.007$ & $40 \pm 5.4$ & $52 \pm 3.5$ & $\mathrm{P}=0.002$ \\
\hline
\end{tabular}

NK, natural killer cells; NS, not statistically significant; SD, standard deviation; IMQ, imiquimod; CD, cluster of differentiation; KLRG1, killer cell lectin-like receptor G1.

ii) activation markers: CD335 (NKp46), CD69, CD28, gp49R, CD45R (B220), CD11c; and iii) markers for cytokine receptors: CD25 (IL-2R $\alpha$ ), CD122 (IL-2R / IL-15R $\beta$ ), CD132 (common $\gamma$ chain).

Analysis of maturation markers (CD11b, CD43, CD27, KLRG1) revealed a significant tendency to increase their expression in NK cells, in both PB and spleen cell suspension, the only exception being CD49b (Fig. 6A and B). The percentages of $\mathrm{CD} 49 \mathrm{~b}^{+} \mathrm{NK} 1.1^{+}$cells in IMQ-treated mice is lower compared to controls in both compartments, PB and spleen, the difference being statistically significant in the spleen $(\mathrm{P}=0.002$; Table II).

Depending on the presence or absence of CD11b and CD27, four stages of maturation of NK cells can be distinguished: immature $\mathrm{NK}$ cells $\left(\mathrm{CD} 27^{-} \mathrm{CD} 11 \mathrm{~b}^{-}\right)$, early mature NK cells $\left(\mathrm{CD} 27^{+} \mathrm{CD} 11 \mathrm{~b}\right)$, mature NK cells $\left(\mathrm{CD} 27^{+} \mathrm{CD} 11 \mathrm{~b}^{+}\right)$ and late mature cells $\left(\mathrm{CD} 27^{-} \mathrm{CD} 1 \mathrm{~b}^{+}\right)$. In our model, in PB, we found significantly decreased values for the immature stages and early mature stages, while the percentages for mature subsets $\left(\mathrm{CD} 27^{+} \mathrm{CD} 11 \mathrm{~b}^{+}\right.$and $\left.\mathrm{CD} 27^{-} \mathrm{CD} 11 \mathrm{~b}^{+}\right)$were higher in IMQ-treated mice compared to the control group, but without statistical significance (Table III). In spleen cells the level of immature NK cells in IMQ-treated mice was significantly decreased, while the values for early mature and completely matured NK cells were increased. The late mature NK population had low values $(52 \pm 4.1$ vs. $56 \pm 3)$ but not statistically significant (Fig. 7A and B).

NKp46 expression on NK cells showed decreased values for IMQ-treated mice as compared to the control group, in both PB $(91 \pm 13.1$ vs. $98 \pm 0.2)$ and spleen cells $(64 \pm 2.7$ vs. $74 \pm 6.9)$. Significant differences for this activating receptor were observed in spleen cells $(\mathrm{P}=0.008$; Table IV, Fig. 8).

Analysis of NK cell activation markers (CD69, B220, CD11c, gp49R, CD28) revealed significantly increased values in spleen cells in IMQ-treated mice as compared to control group (Table IV, Fig. 9B). In PB, of all the tested activation markers, only CD69, CD11c and gp49R showed significantly increased values as compared to the control group (Fig. 9A).

When studying B220 $\mathrm{CD} 11 \mathrm{c}^{+} \mathrm{NK} 1.1^{+}$cell population, a DC subset overlapping functionally with NK cells (37) we found in both PB and spleen cells that their percentage was higher in IMQ-treated mice ( $5 \pm 2$ and $11 \pm 2.2$ vs. $3 \pm 1.3$ and $4 \pm 0.5$ ).

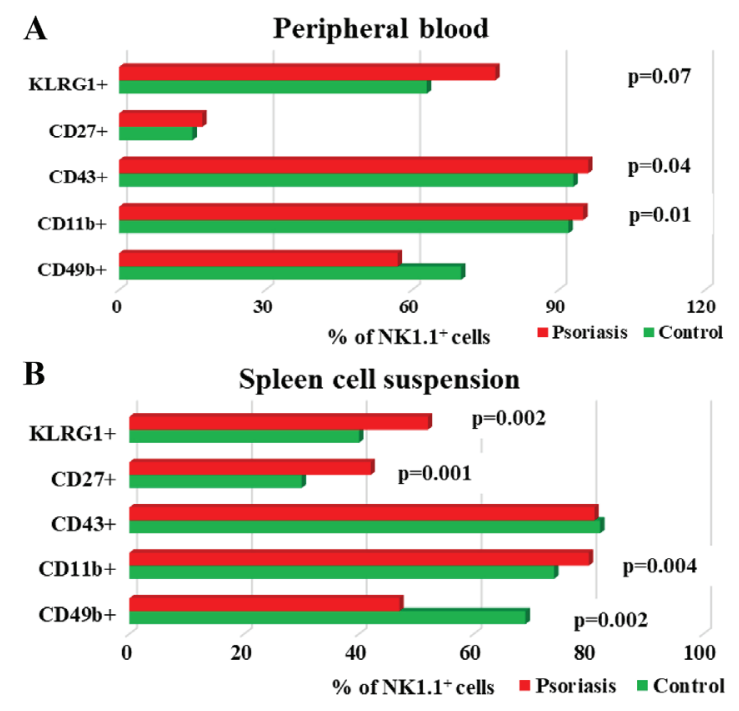

Figure 6. Expression of CD49b, CD11b, CD43, CD27 and KLRG1 levels on NK1. $1^{+}$cells. (A) PB. CD 49b ${ }^{+}, \mathrm{CD}_{11} \mathrm{~b}^{+}, \mathrm{CD} 43^{+}, \mathrm{CD} 27^{+}$and $\mathrm{KLRG}^{+}$cells in IMQ-treated mice $(\mathrm{n}=6)(57 \pm 5.8 ; 95 \pm 1.2, \mathrm{P}=0.01 ; 96 \pm 1.6, \mathrm{P}=0.04 ; 17 \pm 1.9$ and $77 \pm 4.8, \mathrm{P}=0.007)$ compared to control group $(\mathrm{n}=5)(70 \pm 14.1,92 \pm 1.8,93 \pm 2.6$, $15 \pm 3.7$ and $63 \pm 7.6$ ) in PB. (B) Spleen cell suspension. CD49b ${ }^{+}, \mathrm{CD}_{11} \mathrm{~b}^{+}$, $\mathrm{CD}_{4}{ }^{+}, \mathrm{CD}^{2} 7^{+}$and $\mathrm{KLRG}^{+}$cells in IMQ-treated mice $(\mathrm{n}=6)(47 \pm 10.2$, $\mathrm{P}=0.002 ; 80 \pm 3.1, \mathrm{P}=0.004 ; 81 \pm 3.4 ; 42 \pm 3.9, \mathrm{P}=0.001$ and $52 \pm 3.5, \mathrm{P}=0.002)$ compared to control group $(n=5)(69 \pm 4.2,74 \pm 1.4,82 \pm 3,30 \pm 3.7$ and $40 \pm 5.4)$ in spleen cell suspension. The results are presented as a percentage from NK1. $1^{+}$cells (mean $\pm \mathrm{SD}$ ); n, number of mice; IMQ, imiquimod; SD, standard deviation; NK, natural killer cells; CD, cluster of differentiation; KLRG1, killer cell lectin-like receptor G1.

Significant differences between the experimental groups were observed only in spleen cell suspension ( $\mathrm{P}=0.0001$; Fig. 10).

Regarding the distribution of cytokine receptors, the main changes observed in our experimental data for IMQ-treated mice was the significant increase of the receptor for IL-2. This finding was consistent for both of the receptor units (CD132 and $\mathrm{CD} 122)\left(73 \pm 8.3, \mathrm{P}=5 \times 10^{-7}\right.$ vs. $7 \pm 4.3$ and $95 \pm 1, \mathrm{P}=2 \times 10^{-5}$ vs. $89 \pm 1.3$ ) expressed on NK cells from PB. This finding is somewhat to be expected as it comprises the functional units of the same cytokine receptor. CD25 is the $\alpha$ chain of the high-affinity IL-2 receptor and its expression was significantly low in IMQ-treated mice $\left(0.5 \pm 0.2, \mathrm{P}=5 \times 10^{-9}\right)$ as compared with the control mice $(8 \pm 0.6)$ (Fig. $11 \mathrm{~A})$. Contrary to $\mathrm{PB}$, in spleen cells, the levels of CD132 and CD122 are lower in 
Table III. Distribution of NK1.1+ subsets in peripheral blood and spleen suspension.

\begin{tabular}{|c|c|c|c|c|c|c|}
\hline & \multicolumn{3}{|c|}{ Peripheral blood } & \multicolumn{3}{|c|}{ Spleen suspension } \\
\hline & Control $($ mean $\pm \mathrm{SD})$ & IMQ (mean \pm SD) & P-value & Control $($ mean $\pm \mathrm{SD})$ & IMQ $($ mean $\pm \mathrm{SD})$ & P-value \\
\hline $\begin{array}{l}\text { Immature } \\
\left(\mathrm{CD} 27^{-} \mathrm{CD} 11 \mathrm{~b}^{-}\right)\end{array}$ & $6 \pm 1.6$ & $3 \pm 0.7$ & $\mathrm{P}=0.001$ & $14 \pm 1.4$ & $7 \pm 0.8$ & $\mathrm{P}=3 \times 10^{-6}$ \\
\hline $\begin{array}{l}\text { Early mature } \\
\left(\mathrm{CD} 27^{+} \mathrm{CD} 11 \mathrm{~b}^{-}\right)\end{array}$ & $4 \pm 1.5$ & $2 \pm 0.5$ & $\mathrm{P}=0.004$ & $10 \pm 1.5$ & $13 \pm 2.4$ & NS \\
\hline $\begin{array}{l}\text { Mature } \\
\left(\mathrm{CD} 27^{+} \mathrm{CD} 11 \mathrm{~b}^{+}\right)\end{array}$ & $11 \pm 2.4$ & $14 \pm 1.7$ & NS & $20 \pm 3.4$ & $29 \pm 3.2$ & $\mathrm{P}=0.002$ \\
\hline $\begin{array}{l}\text { Late mature } \\
\left(\mathrm{CD} 27^{-} \mathrm{CD} 11 \mathrm{~b}^{+}\right)\end{array}$ & $78 \pm 5.3$ & $82 \pm 1.5$ & NS & $56 \pm 3$ & $52 \pm 4.1$ & NS \\
\hline
\end{tabular}

NK, natural killer cells; NS, not statistically significant; SD, standard deviation; IMQ, imiquimod; CD, cluster of differentiation.

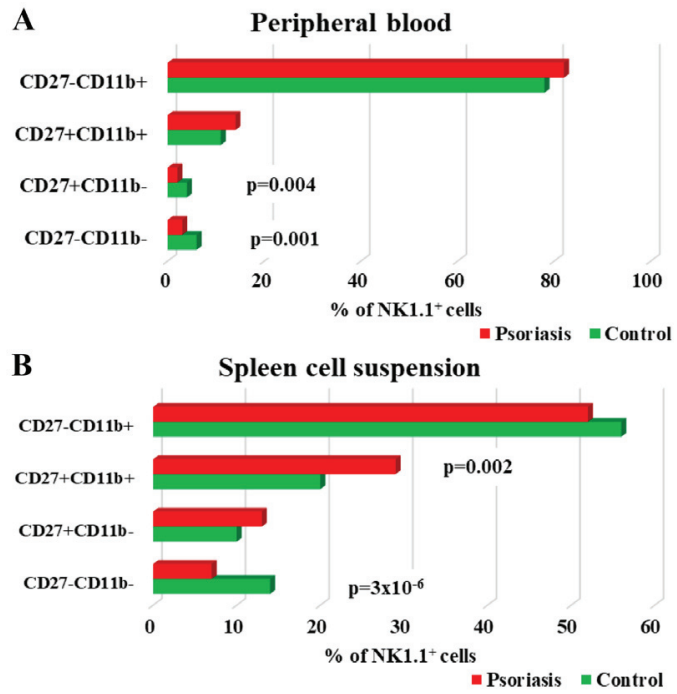

Figure 7. CD27CD11bNK1.1 $1^{+}$subpopulations in $\mathrm{PB}$ and spleen cell suspension. (A) PB. Distribution of CD27 CD11b , CD27 ${ }^{+} \mathrm{CD} 11 \mathrm{~b}-$, CD $27^{+} \mathrm{CD} 11 \mathrm{~b}$ and $\mathrm{CD} 27^{-} \mathrm{CD} 11 \mathrm{~b}^{+} \mathrm{NK} 1.1^{+}$cells in IMQ-treated mice $(\mathrm{n}=6)(3 \pm 0.7, \mathrm{P}=0.001$; $2 \pm 0.5, \mathrm{P}=0.004 ; 14 \pm 1.7$ and $82 \pm 1.5)$ compared to control group $(\mathrm{n}=5)(6 \pm 1.6$ $4 \pm 1.5,11 \pm 2.4$ and $78 \pm 5.3$ ) in PB. (B) Spleen cell suspension. Distribution of CD $27^{-} \mathrm{CD}_{11 \mathrm{~b}}^{-}, \mathrm{CD} 27^{+} \mathrm{CD} 11 \mathrm{~b}-\mathrm{CD} 27^{+} \mathrm{CD} 11 \mathrm{~b}^{+}$and CD $27^{-} \mathrm{CD} 11 \mathrm{~b}^{+} \mathrm{NK} 1.1^{+}$cells in IMQ-treated mice $(\mathrm{n}=6)\left(7 \pm 0.8, \mathrm{P}=3 \times 10^{-6} ; 13 \pm 2.4 ; 29 \pm 3.2, \mathrm{P}=0.002\right.$ and $52 \pm 4.1)$ compared to control group $(n=5)(14 \pm 1.4,10 \pm 1.5,20 \pm 3.4$ and $56 \pm 3)$ in spleen cell suspension. The results are presented as a percentage from NK1.1 $1^{+}$cells (mean $\pm \mathrm{SD}$ ). $n$, number of mice; PB, peripheral blood; IMQ, imiquimod; SD, standard deviation; NK, natural killer cells; $\mathrm{CD}$, cluster of differentiation.

IMQ-treated mice $(16 \pm 4.4 ; 75 \pm 8, \mathrm{P}=0.004)$ than in the control group $(18 \pm 3.6 ; 91 \pm 2.6)$, as well as in PB. The level of CD25 was found increased $(6 \pm 1.5$ vs. $2 \pm 0.6)$ but not statistically significant (Fig. 11B).

\section{Discussion}

IMQ-based mice model of psoriasiform dermatitis replicates human Ps in terms of skin inflammation and disease severity assessed by erythema, desquamation, induration parameters, PASI modified score and histopathological evaluation (hyperkeratosis, parakeratosis, acanthosis and elongation of rete ridges). Moreover, the mouse model displays splenomegaly and altered NK populations related to the severity of the disease.

In our previous study regarding psoriasiform dermatitis in a mouse model, we investigated immunological changes induced by IMQ topical application in lymphocyte populations from PB and spleen (34). One of the main observed changes was the significant decrease of $\mathrm{NK} 1.1^{+}$cell percentages, which led to the present study to investigate complex phenotypic pattern of circulating and spleen resident NK. Using flow-cytometry, we investigated a large panel of surface markers: maturation and activation markers (CD49b, CD11b, CD43, CD27, KLRG1, NKp46, CD69, CD28, gp49R, CD45R, CD11c) and markers for cytokine receptors (CD25, CD122, CD132). To our knowledge there is no similar study regarding NK cells in blood and spleen cells in an IMQ-based mouse model. We have previously used this panel to characterize NK cells in another mouse model of skin cancer, namely in cutaneous melanoma bearing mice (38).

Murine NK cells develop in specialized bone marrow niches and derive from common lymphoid progenitor, going through three important stages: NK cell progenitors (pre-NK cell precursors and refined-NK cell precursors), immature NK cells (stage A-C) and mature NK cells (stage D-F). Early stages are characterized by the expression of IL-7R $\alpha$ (CD127), CD27, CD244 and CD122, while the acquisition of NKG2D, CD27 (stage A), NK1.1, CD43, CD62L, CD226 (stage B) and NCR1 (stage C) marks the conversion to immature NK cells. Mature NK cells further express CD49b, Ly49 (stage D), loose CD43 and acquire CD11b (stage E) and in the final stage of maturation (stage F) downregulate CD27 and acquire KLRG1 (39). KLRG1 is a C-type lectin inhibitory receptor (also expressed on subsets of $\mathrm{T}$ cells) allowing identification of NK terminal development stages and is associated with diminished proliferation and effector functions (40).

In our model, analysis of maturation markers (CD11b, CD43, CD27, KLRG1) revealed a significant tendency to increase their expression on NK cells, in both PB and spleen cell suspension with the exception of CD49b. The percentage of CD $49 \mathrm{~b}^{+} \mathrm{NK} 1.1^{+}$cells in IMQ-treated mice is significantly lower than in the controls in spleen cell suspension. This finding agrees with another recently reported study where 
Table IV. Distribution of activation markers on NK1.1+ cells in peripheral blood and spleen suspension.

\begin{tabular}{|c|c|c|c|c|c|c|}
\hline & \multicolumn{3}{|c|}{ Peripheral blood } & \multicolumn{3}{|c|}{ Spleen suspension } \\
\hline & Control (mean $\pm \mathrm{SD})$ & $\mathrm{IMQ}($ mean $\pm \mathrm{SD})$ & P-value & Control (mean \pm SD) & IMQ (mean \pm SD) & P-value \\
\hline NKp46 & $98 \pm 0.2$ & $91 \pm 13.1$ & NS & $74 \pm 6.9$ & $64 \pm 2.7$ & $\mathrm{P}=0.008$ \\
\hline CD69 & $12 \pm 1.4$ & $60 \pm 13$ & $\mathrm{P}=0.005$ & $2 \pm 0.2$ & $62 \pm 3$ & $\mathrm{P}=1 \times 10^{-10}$ \\
\hline B220 & $7 \pm 2.6$ & $6 \pm 2$ & NS & $9 \pm 0.8$ & $14 \pm 2.2$ & $\mathrm{P}=0.003$ \\
\hline CD11c & $25 \pm 2.4$ & $66 \pm 11$ & $\mathrm{P}=6 \times 10^{-5}$ & $21 \pm 0.6$ & $76 \pm 6.2$ & $\mathrm{P}=1 \times 10^{-7}$ \\
\hline gp49R & $1 \pm 0.3$ & $11 \pm 7$ & $\mathrm{P}=0.02$ & $1 \pm 0.5$ & $23 \pm 5.7$ & $\mathrm{P}=5 \times 10^{-5}$ \\
\hline CD28 & $0.4 \pm 0$ & $3 \pm 2$ & NS & $0.5 \pm 0.2$ & $33 \pm 6.3$ & $\mathrm{P}=8 \times 10^{-6}$ \\
\hline
\end{tabular}

NK, natural killer cells; NS, not statistically significant; SD, standard deviation; IMQ, imiquimod; CD, cluster of differentiation.

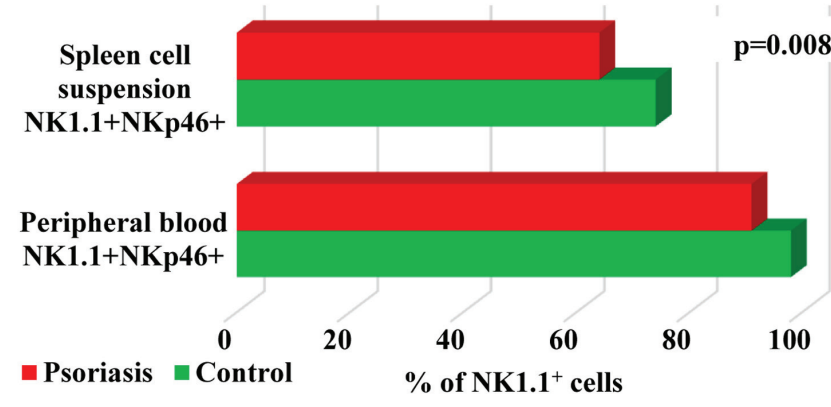

Figure 8. NK1.1 $1^{+} \mathrm{NK} 46^{+}$distribution in $\mathrm{PB}$ and spleen cell suspension. $\mathrm{NK} 1.1^{+} \mathrm{NKp} 46^{+}$cells in IMQ-treated mice $(\mathrm{n}=6)$ in $\mathrm{PB}(91 \pm 13.1)$ and spleen cell suspension $(64 \pm 2.7, \mathrm{P}=0.008)$ compared to control group $(\mathrm{n}=5)(98 \pm 0.2$ in PB; $74 \pm 6.9$ in spleen cell suspensions). The results are presented as percentage from NK1.1+ cells (mean $\pm \mathrm{SD}$ ); $\mathrm{n}$, number of mice; $\mathrm{PB}$, peripheral blood; IMQ, imiquimod; SD, standard deviation; NK, natural killer cells.

$\mathrm{CD}_{49} \mathrm{~b}^{+}$was found low on $\mathrm{T}$ cells in psoriatic patients, this decrease being correlated with the severity of the disease (41).

Depending on the presence or absence of CD11b and CD27, there are several maturation stages of NK cells. CD27 $\mathrm{NK}$ cell subsets display a greater effector function and responsiveness to chemokines then $\mathrm{CD} 27^{-} \mathrm{NK}$ cell subsets. $\mathrm{CD} 27^{-} \mathrm{CD} 1 \mathrm{~b}^{+} \mathrm{NK}$ cell subsets represent the final stage of maturation (42). In PB, our experimental data revealed significant decreased values for the immature stages, while the percentages for mature subsets were higher in IMQ-treated mice than in control group, but without statistical significance. In spleen cell suspension the level of immature NK cells in IMQ-treated mice was significantly decreased $\left(\mathrm{P}=3 \times 10^{-6}\right)$, while the values increased for early mature and mature $(\mathrm{P}=0.002) \mathrm{NK}$ cells, and in the final stage of maturation, the values were low but not statistically significant. This finding reflects the immune engagement toward activatory profile of NK cells and draws attention to evaluate Ps intensity correlated with the mature profile of circulating NK cells.

NKp46 (similar NCR1 or CD335), a major activating receptor, is an NK cell specific surface marker and is found on all mature NK cells. It is part of natural cytotoxicity receptor group together with NKp44 and NKp30 (43). It is involved in human NK cell activation, in tumor cell recognition and plays an important role in natural cytotoxicity against different

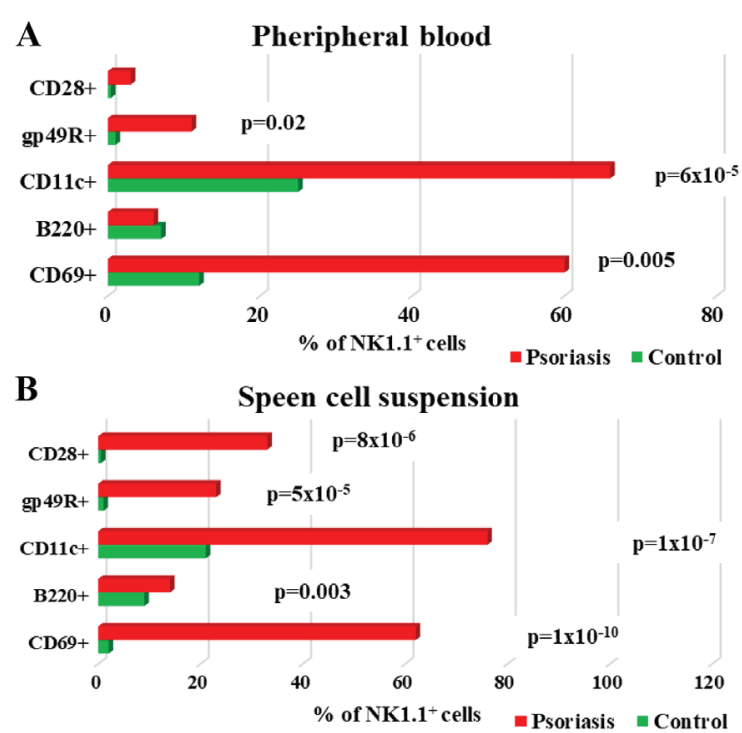

Figure 9. Expression of CD69, B220, CD11c, gp49R and CD28 levels on NK1.1 $1^{+}$cells; (A) PB. CD69 ${ }^{+}, \mathrm{B} 220^{+}, \mathrm{CD} 11 \mathrm{c}^{+}, \mathrm{gp} 49 \mathrm{R}^{+}$and $\mathrm{CD} 28^{+}$cells in IMQ-treated mice $(n=6)\left(60 \pm 13, P=0.005 ; 6 \pm 2 ; 66 \pm 11, P=6 \times 10^{-5} ; 11 \pm 7\right.$, $\mathrm{P}=0.02$ and $3 \pm 2)$ compared to control group $(\mathrm{n}=5)(12 \pm 1.4 ; 7 \pm 2.6 ; 25 \pm 2.4$; $1 \pm 0.3$ and $0.4 \pm 0$ ) in PB. (B) Spleen cell suspension. CD69 $9^{+}, \mathrm{B} 220^{+}, \mathrm{CD} 11 \mathrm{c}^{+}$, gp49R $\mathrm{R}^{+}$and $\mathrm{CD} 28^{+}$cells in IMQ-treated mice $(\mathrm{n}=6)\left(62 \pm 3, \mathrm{P}=1 \times 10^{-10}\right.$; $14 \pm 2.2, \mathrm{P}=0.003 ; 76 \pm 6.2, \mathrm{P}=1 \times 10^{-7} ; 23 \pm 5.7, \mathrm{P}=5 \times 10^{-5}$ and $33 \pm 6.3, \mathrm{P}=8 \times 10^{-6}$ ) compared to control group $(\mathrm{n}=5)(2 \pm 0.2 ; 9 \pm 0.8 ; 21 \pm 0.6 ; 1 \pm 0.5$ and $0.5 \pm 0.2)$ in spleen cell suspension. The results are presented as a percentage from $\mathrm{NK} 1.1^{+}$cells $($mean $\pm \mathrm{SD})$; $\mathrm{n}$, number of mice; PB, peripheral blood; IMQ, imiquimod; SD, standard deviation; NK, natural killer cells; $\mathrm{CD}$, cluster of differentiation.

tumor target cells (44). Our data showed a decreased NKp46 expression on NK cells for IMQ-treated mice as compared to the control group, in both PB and spleen cell suspensions. The finding is not surprising because, as already mentioned, the maturation and activation of NK cells are characteristics of our psoriatic mouse model.

In addition to NKp46, our study also included other relevant markers to NK cell activation such as CD69, B220, CD11c, gp49R and CD28. Leukocyte activation receptor CD69, also called very early antigen, was found on human NK cells from psoriatic lesions inflammatory infiltrate. Most of these NK cells had a CD56 ${ }^{\text {bright }}$ phenotype and are known to produce in vitro large quantities of IFN $\gamma$ as a response to IL-2 stimulation (45). 


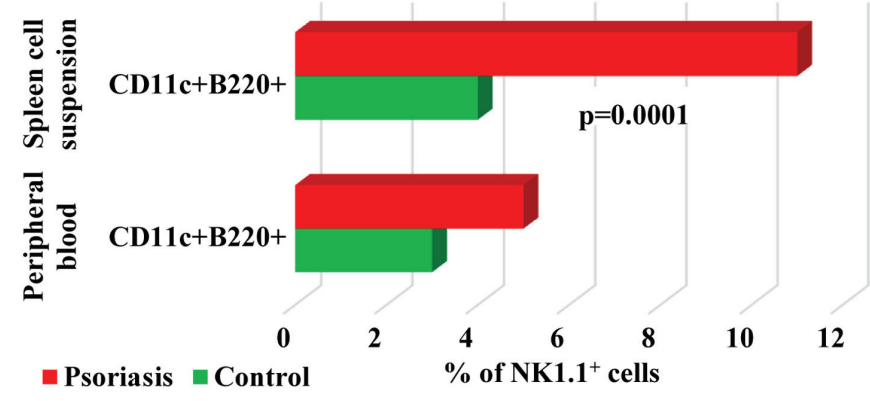

Figure 10. NK $1.1^{+} \mathrm{CD} 11 \mathrm{c}^{+} \mathrm{B} 220^{+}$cells in $\mathrm{PB}$ and spleen cell suspension. Distribution of $\mathrm{NK} 1.1^{+} \mathrm{CD} 11 \mathrm{c}^{+} \mathrm{B} 220^{+}$cells in IMQ-treated mice $(\mathrm{n}=6)$ in $\mathrm{PB}(5 \pm 2)$ and spleen cell suspension $(11 \pm 2.2, \mathrm{P}=0.0001)$ compared with the control group $(n=5)(3 \pm 1.3$ in $P B$ and $4 \pm 0.5$ in spleen cell suspensions). The results are presented as percentage from NK1.1 $1^{+}$cells (mean $\pm \mathrm{SD}$ ); n, number of mice; PB, peripheral blood; IMQ, imiquimod; SD, standard deviation; NK, natural killer cells.
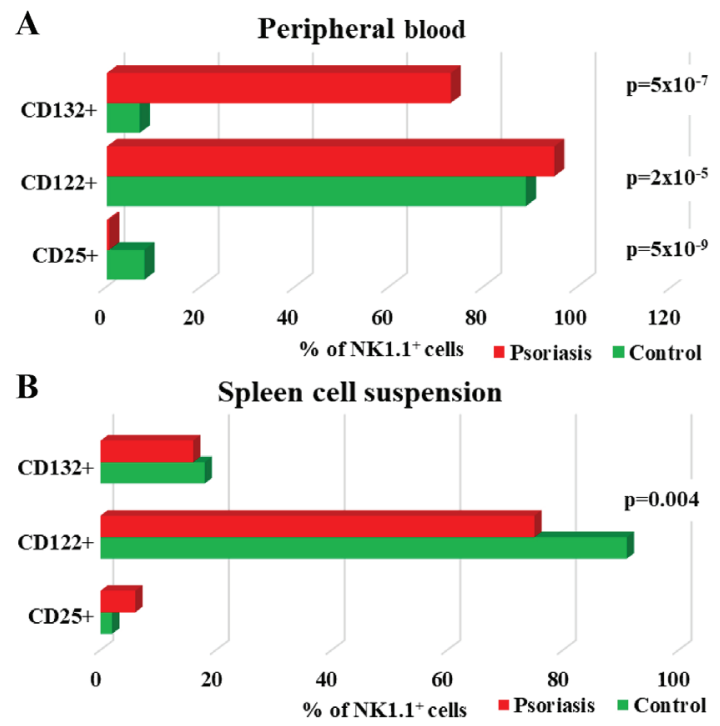

Figure 11. Expression of CD25, CD122 and CD132 levels for NK1.1 $1^{+}$cells. (A) PB. CD25 $5^{+}$CD122 $2^{+}$and $\mathrm{CD} 132^{+} \mathrm{NK} 1.1^{+}$cells in IMQ-treated mice ( $\mathrm{n}=6)\left(0.5 \pm 0.2, \mathrm{P}=5 \times 10^{-9} ; 95 \pm 1, \mathrm{P}=2 \times 10^{-5}\right.$ and $\left.73 \pm 8.3, \mathrm{P}=5 \times 10^{-7}\right)$ compared to control group $(\mathrm{n}=5)(8 \pm 0.6,89 \pm 1.3$ and $7 \pm 4.3)$ in PB. (B) Spleen cell suspension. CD25 $5^{+} \mathrm{CD} 122^{+}$and $\mathrm{CD} 132^{+} \mathrm{NK} 1.1^{+}$cells in IMQ-treated mice $(\mathrm{n}=6)$ $(6 \pm 1.5 ; 75 \pm 8, P=0.004$ and $16 \pm 4.4)$ compared to control group $(n=5)(2 \pm 0.6$ $91 \pm 2.6$ and $18 \pm 3.6)$ in spleen cell suspension. The results are presented as a percentage from NK1.1 $1^{+}$cells (mean $\pm \mathrm{SD}$ ); $\mathrm{n}$, number of mice; $\mathrm{PB}$, peripheral blood; IMQ, imiquimod; SD, standard deviation; NK, natural killer cells; $\mathrm{CD}$, cluster of differentiation.

Murine NK cells also express inhibitory receptors belonging to Ig superfamily-related (gp49) receptors. Activated NK cells express gp49B receptor which displays structural homology with human killer inhibitory receptors (46). CD28, a cell surface molecule with a critical role in $\mathrm{T}$ cell activation is also expressed by mouse NK cells, and its triggering NK cell proliferation, cytotoxicity, and cytokine secretion (47). Analysis of activation markers of NK cells (CD69, B220, CD11c, gp49R, CD28) revealed significant increased values in spleen cell suspension in IMQ-treated mice as compared to control group. In PB, only CD69, CD11c and gp49R showed significantly increased values as compared to the control group. The finding reveals that psoriatic lesions can induce high activation in secondary lymph organs. When evaluated in periphery, only CD69, CD11c and gp49R showed significant increased values as compared to control group. In an attempt to obtain a panel of peripheral immune cells that can be applied further to Ps patients a thorough selection of significant activation should be done because although lymphoid organs display a high activation pattern, in periphery only selected activated populations can be identified.

B220 ${ }^{+} \mathrm{CD} 11 \mathrm{c}^{+} \mathrm{NK} 1.1^{+}$cells appear to be the equivalent of human $\mathrm{CD} 56^{\text {bright }} \mathrm{NK}$ cells due to their ability to produce higher levels of IFN $\gamma$ (37). The percentages of $\mathrm{B} 220^{+} \mathrm{CD} 11 \mathrm{c}^{+} \mathrm{NK} 1.1^{+}$ subset in both $\mathrm{PB}$ and spleen cell suspension was higher in IMQ-treated mice than in control mice, finding that emphasizes once more the activation of this lymphocyte subset. Moreover the cytokine network that is triggered by $\mathrm{NK}$ activation can act on the cells by themselves in an autocrine manner and/or can influence other important players in the immune response. Thus, the cytokine network is particularly important for the proliferation, activation and functional capacity of NK cells. In our study, we investigated the distribution of three cytokine receptors: CD25 (IL-2R $\alpha$ ), CD122 (IL-2R/IL-15R $\beta$ ), CD132 (common $\gamma$ chain-IL-2, IL-4, IL-7, IL-9, IL-15, IL-21). The main changes observed in our experimental data for IMQ-treated mice were the significant increase of CD132 $\left(\mathrm{P}=5 \times 10^{-7}\right)$ and CD122 $\left(\mathrm{P}=2 \times 10^{-5}\right)$ expression on NK cells in PB. The expression of CD25 is significantly low in IMQ-treated mice as compared with the control mice. In spleen cells, the levels of CD132 and CD122 are lower in IMQ-treated mice than in the control group, as well as in PB. The level of CD25 increased but was not statistically significant. As we have an inverse correlation of these cytokine receptors we can postulate that there is a flux of activated cells toward periphery from the secondary lymphoid organs that are drawn toward the induced psoriatic lesions. IL-17 plays a leading role in the pathogenesis of Ps and in the concert of cells that secrete this regulatory cytokine, NK cells are one of the main cells (48). IL-17 has a heterodimeric receptor IL-17RA/IL-17RC located on non-immune cells such as keratinocytes, endothelial cells and fibroblasts and if IL-17 increases the Ps prognosis is not favorable as it is sustaining the development of psoriatic lesions. This finding correlates with the decrease of IL-2 circulatory level, recently reported in psoriatic patients (49). We can again postulate that there is a negative regulation in psoriatic disease where NK cells balance this cytokine axes IL-17-IL-2 and if this balance is deregulated activation of non-immune cells, e.g., keratinocytes, is induced and the psoriatic lesions appear.

Taking into account that there is a continuous search for developing new therapy targets in Ps (50) and that NK cells can be future modulatory targets $(26,27)$ finding new markers that can aid the dermatologists in clinical management (51-53) would lead to novel cellular pattern for monitoring this auto-immune disease.

In conclusion, imiquimod-based murine model of psoriasiform dermatitis was analysed in order to evaluate the involvement of NK cells in the pathogenesis of this autoimmune disease. Evaluating a large panel of NK surface markers from the maturation and activation sets along with markers for cytokine receptors we obtained important differences in experimentally induced mouse NK cell phenotypes as compared to the control group, reflecting high activation in correlation with the degree of the psoriatic lesions. Our evaluation was intended to shed light on the involvement of 
NK functionality in Ps development and draw some outlines regarding NK as disease evolution cellular marker.

\section{Acknowledgements}

The presented study will be integrated into the original part of PhD thesis of author Mihaela Surcel.

\section{Funding}

This study was supported by Grants PN 19.29.01.01, PN 19.29.02.03, PN-III-P1-1.2-PCCDI-2017-0341/2018, Grant COP A 1.2.3., ID: P_40_197/2016, Ctr. 52/2016 and by Ministry of Research and Innovation in Romania, under Program 1-The Improvement of the National System of Research and Development, Subprogram 1.2-Institutional Excellence-Projects of Excellence Funding in RDI, Contract no. 7PFE/16.10.2018.

\section{Availability of data and materials}

The data sets used and/or analysed during the present study are available from the corresponding author on reasonable request.

\section{Authors' contributions}

MS, RIH, GI, MN and MC: research creation and design, data acquisition, analysis and interpretation of data, statistical analysis, manuscript drafting, critical revision of the manuscript for important intellectual content. ANM, IRP, OB, CarC, LS, IZ and ConC: interpretation of data, manuscript drafting, critical revision of the manuscript for important intellectual content. All authors read and approved the final manuscript.

\section{Ethics approval and consent to participate}

The study protocol was approved by the Ethics Committee of 'Victor Babeș' National Institute of Pathology.

\section{Patient consent for publication}

Not applicable.

\section{Competing interests}

The authors declare that they have no competing interests.

\section{References}

1. Boehncke WH and Schön MP: Psoriasis. Lancet 386: 983-994, 2015.

2. Dowlatshahi EA, van der Voort EAM, Arends LR and Nijsten T: Markers of systemic inflammation in psoriasis: A systematic review and meta-analysis. Br J Dermatol 169: 266-282, 2013.

3. Parisi R, Symmons DPM, Griffiths CEM and Ashcroft DM Identification and Management of Psoriasis and Associated ComorbidiTy (IMPACT) project team: Global epidemiology of psoriasis: A systematic review of incidence and prevalence. J Invest Dermatol 133: 377-385, 2013.

4. Cohen AD, Dreiher J, Shapiro Y, Vidavsky L, Vardy DA, Davidovici B and Meyerovitch J: Psoriasis and diabetes: A population-based cross-sectional study. J Eur Acad Dermatol Venereol 22: 585-589, 2008.
5. Armstrong AW, Harskamp CT and Armstrong EJ: The association between psoriasis and obesity: A systematic review and meta-analysis of observational studies. Nutr Diabetes 2: e54, 2012.

6. Shah K, Mellars L, Changolkar A and Feldman SR: Real-world burden of comorbidities in US patients with psoriasis. J Am Acad Dermatol 77: 287-292.e4, 2017.

7. Kölliker Frers RA, Bisoendial RJ, Montoya SF, Kerzkerg E, Castilla R, Tak PP, Milei J and Capani F: Psoriasis and cardiovascular risk: Immune-mediated crosstalk between metabolic, vascular and autoimmune inflammation. IJC Metab Endocr 6: 43-54, 2015.

8. Møller AH, Erntoft S, Vinding GR and Jemec GB: A systematic literature review to compare quality of life in psoriasis with other chronic diseases using EQ-5D-derived utility values. Patient Relat Outcome Meas 6: 167-177, 2015.

9. Caruntu C, Boda D, Dumitrascu G, Constantin C and Neagu M: Proteomics focusing on immune markers in psoriatic arthritis. Biomarkers Med 9: 513-528, 2015.

10. Wolf P, Weger W, Patra V, Gruber-Wackernagel A and Byrne SN: Desired response to phototherapy vs photoaggravation in psoriasis: What makes the difference? Exp Dermatol 25: 937-944, 2016.

11. Dalkilic E, Bulbul Baskan E, Alkis N, Gullulu M, Yavuz M, Dilek K, Ersoy A and Yurtkuran M: Tumor necrosis factor-alpha antagonist therapy-induced psoriasis in Turkey: Analysis of 514 patients. Mod Rheumatol 22: 738-742, 2012.

12. Tatu AL and Nwabudike LC: Metoprolol-associated onset of psoriatic arthropathy. Am J Ther 24: e370-e371, 2017.

13. Moriwaki Y, Takada K, Tsuji S, Kawashima K and Misawa H: Transcriptional regulation of SLURP2, a psoriasis-associated gene, is under control of IL-22 in the skin: A special reference to the nested gene LYNX1. Int Immunopharmacol 29: 71-75, 2015.

14. Wheatley R, Brooks J, Stumpf B and Boh E: Obesity, diet, and inflammation in psoriasis. J Psoriasis Psoriatic Arthritis 2: 97-101, 2017.

15. Farkas A and Kemény L: Alcohol, liver, systemic inflammation and skin: A focus on patients with psoriasis. Skin Pharmacol Physiol 26: 119-126, 2013.

16. Fry L and Baker BS: Triggering psoriasis: The role of infections and medications. Clin Dermatol 25: 606-615, 2007.

17. Zeng J, Luo S, Huang Y and Lu Q: Critical role of environmental factors in the pathogenesis of psoriasis. J Dermatol 44: 863-872, 2017.

18. Mrowietz U and Reich K: Psoriasis - new insights into pathogenesis and treatment. Dtsch Arztebl Int 106: 11-18, quiz 19, 2009.

19. Carrascosa JM, Jacobs I, Petersel D and Strohal R: Biosimilar drugs for psoriasis: Principles, present, and near future. Dermatol Ther (Heidelb) 8: 173-194, 2018.

20. Niculet E, Neculia GV, Tatu AL and Buzia OD: Curcumin-extraction, physical and chemical analysis, formulas and control. basic methods for further research. Mater Plast 55: 672-675, 2018.

21. Nwabudike LC and Tatu AL: Using complementary and alternative medicine for the treatment of psoriasis. A step in the right direction. JAMA Dermatol: Mar 13, 2019 (Epub ahead of print).

22. Karczewski J, Dobrowolska A, Rychlewska-Hańczewska A and Adamski Z: New insights into the role of T cells in pathogenesis of psoriasis and psoriatic arthritis. Autoimmunity 49: 435-450, 2016.

23. Surcel M, Huica R, Constantin C, Ursaciuc C and Neagu M: Biomarkers insights in psoriasis - Regulatory cytokines. Curr Biomark 7: 3-11, 2017.

24. Mahil SK, Capon F and Barker JN: Update on psoriasis immunopathogenesis and targeted immunotherapy. Semin Immunopathol 38: 11-27, 2016.

25. Caligiuri MA: Human natural killer cells. Blood 112: 461-469, 2008.

26. Dunphy SE, Sweeney CM, Kelly G, Tobin AM, Kirby B and Gardiner CM: Natural killer cells from psoriasis vulgaris patients have reduced levels of cytotoxicity associated degranulation and cytokine production. Clin Immunol 177: 43-49, 2017.

27. von Bubnoff D, Andrès E, Hentges F, Bieber T, Michel T and Zimmer J: Natural killer cells in atopic and autoimmune diseases of the skin. J Allergy Clin Immunol 125: 60-68, 2010.

28. Takahashi H, Amagai M, Tanikawa A, Suzuki S, Ikeda Y, Nishikawa T, Kawakami Y and Kuwana M: Thelper type 2-biased natural killer cell phenotype in patients with pemphigus vulgaris. J Invest Dermatol 127: 324-330, 2007. 
29. Zakka LR, Fradkov E, Keskin DB, Tabansky I, Stern JNH and Ahmed AR: The role of natural killer cells in autoimmune blistering diseases. Autoimmunity 45: 44-54, 2012.

30. Bocheńska K, Smolińska E, Moskot M, Jakóbkiewicz-Banecka J and Gabig-Cimińska M: Models in the research process of psoriasis. Int J Mol Sci 18: E2514, 2017.

31. Banerjee S and Kaunelis D: Imiquimod for the treatment of genital warts: A review of clinical effectiveness and cost-effectiveness. In: CADTH Rapid Response Report: Summary with critical appraisal. Canadian Agency for Drugs and Technologies in Health, Ottawa, ON, 2017.

32. Bhatta AK, Wang P, Keyal U, Zhao Z, Ji J, Zhu L, Wang X and Zhang G: Therapeutic effect of Imiquimod enhanced ALA-PDT on cutaneous squamous cell carcinoma. Photodiagnosis Photodyn Ther 23: 273-280, 2018.

33. Banerjee $S$ and Kaunelis D: Imiquimod for the treatment of actinic keratosis: A review of clinical effectiveness and cost-effectiveness. In: CADTH Rapid Response Report: Summary with critical appraisal. Canadian Agency for Drugs and Technologies in Health, Ottawa, ON, 2017.

34. Surcel M, Huică R-I, Munteanu AN, Isvoranu G, Pîrvu IR, Ciotaru D, Constantin C, Bratu O, Căruntu C, Neagu M, et al: Phenotypic changes of lymphocyte populations in psoriasiform dermatitis animal model. Exp Ther Med 17: 1030-1038, 2019

35. National Research Council (US) Committee for the Update of the Guide for the Care and Use of Laboratory Animals: Guide for the Care and Use of Laboratory Animals, 8th edition. National Academies Press (US), Washington, DC, 2011.

36. van der Fits L, Mourits S, Voerman JSA, Kant M, Boon L, Laman JD, Cornelissen F, Mus AM, Florencia E, Prens EP, et al: Imiquimod-induced psoriasis-like skin inflammation in mice is mediated via the IL-23/IL-17 axis. J Immunol 182: 5836-5845, 2009.

37. Blasius AL, Barchet W, Cella M and Colonna M: Development and function of murine B220+CD11c+NK1.1+ cells identify them as a subset of NK cells. J Exp Med 204: 2561-2568, 2007.

38. Isvoranu G, Surcel M, Huică R-I, Munteanu AN, Pîrvu IR, Ciotaru D, Constantin C, Bratu O, Neagu M and Ursaciuc C: Natural killer cell monitoring in cutaneous melanoma - new dynamic biomarker. Oncol Lett 17: 4197-4206, 2019.

39. Abel AM, Yang C, Thakar MS and Malarkannan S: Natural killer cells: Development, maturation, and clinical utilization. Front Immunol 9: 1869, 2018.

40. Huntington ND, Tabarias H, Fairfax K, Brady J, Hayakawa Y, Degli-Esposti MA, Smyth MJ, Tarlinton DM and Nutt SL: NK cell maturation and peripheral homeostasis is associated with KLRG1 up-regulation. J Immunol 178: 4764-4770, 2007.

41. Kim J, Lee J, Gonzalez J, Fuentes-Duculan J, Garcet S and Krueger JG: Proportion of CD4+CD49b+LAG-3+ Type 1 regulatory T cells in the blood of psoriasis patients inversely correlates with psoriasis area and severity index. J Invest Dermatol 138: 2669-2672, 2018.
42. Chiossone L, Chaix J, Fuseri N, Roth C, Vivier E and Walzer T: Maturation of mouse NK cells is a 4-stage developmental program. Blood 113: 5488-5496, 2009.

43. Hadad U, Thauland TJ, Martinez OM, Butte MJ, Porgador A and Krams SM: NKp46 clusters at the immune synapse and regulates NK cell polarization. Front Immunol 6: 495, 2015.

44. Pessino A, Sivori S, Bottino C, Malaspina A, Morelli L, Moretta L, Biassoni R and Moretta A: Molecular cloning of NKp46: A novel member of the immunoglobulin superfamily involved in triggering of natural cytotoxicity. J Exp Med 188: 953-960, 1998

45. Dunphy S and Gardiner CM: NK cells and psoriasis. J Biomed Biotechnol 2011: 248317, 2011

46. Wang LL, Chu DT, Dokun AO and Yokoyama WM: Inducible expression of the gp49B inhibitory receptor on NK cells. J Immunol 164: 5215-5220, 2000.

47. Nandi D, Gross JA and Allison JP: CD28-mediated costimulation is necessary for optimal proliferation of murine NK cells. J Immunol 152: 3361-3369, 1994.

48. Georgescu SR, Tampa M, Caruntu C, Sarbu MI, Mitran CI, Mitran MI, Matei C, Constantin C and Neagu M: Advances in understanding the immunological pathways in psoriasis. Int J Mol Sci 20: E739, 2019.

49. Solberg SM, Sandvik LF, Eidsheim M, Jonsson R, Bryceson YT and Appel S: Serum cytokine measurements and biological therapy of psoriasis - Prospects for personalized treatment? Scand J Immunol 88: e12725, 2018.

50. Guarene M, Pasi A, Bolcato V, Cananzi R, Piccolo A, Sbarsi I, Klersy C, Cacciatore R and Brazzelli V: The presence of HLA-A Bw4-80I KIR ligands could predict 'Difficult-to-Treat' psoriasis and poor response to Etanercept. Mol Diagn Ther 22: 471-474, 2018.

51. Batani A, Brănisteanu DE, Ilie MA, Boda D, Ianosi S, Ianosi G and Caruntu C: Assessment of dermal papillary and microvascular parameters in psoriasis vulgaris using in vivo reflectance confocal microscopy. Exp Ther Med 15: 1241-1246, 2018.

52. Căruntu C, Boda D, Căruntu A, Rotaru M, Baderca F and Zurac S: In vivo imaging techniques for psoriatic lesions. Rom J Morphol Embryol 55 (Suppl): 1191-1196, 2014.

53. Negrei C, Căruntu C, Ginghină O, Burcea Dragomiroiu GTA, Toderescu CD and Boda D: Qualitative and quantitative determination of methotrexate polyglutamates in erythrocytes by high performance liquid chromatography. Rev Chim Buchar 66: 607-610, 2015

This work is licensed under a Creative Commons Attribution-NonCommercial-NoDerivatives 4.0 International (CC BY-NC-ND 4.0) License. 